\title{
NEGACIÓN Y VINDICACIÓN DEL TEATRO DE JORGE ISAACS
}

Negation and vindication of the Jorge Isaacs's theatre

\section{Por: Mauricio Doménici}

Profesor del Departamento de Artes Escénicas

Facultad de Artes Integradas

Universidad del Valle

domenici.m@gmail.com

Resumen: Este artículo es el resultado de una investigación sobre el teatro desconocido de Jorge Isaacs. La crítica tradicional valoró negativamente la dramaturgia de sus tres obras, inscritas en la estética romántica de mediados del Siglo XIX. Al resituar este teatro en el contexto cultural y político de su tiempo, se revela la significación histórica de un teatro cuya carga polémica se ha desconocido y negado, bajo la acusación de haber sido un teatro "afrancesado" y "extranjerizante". Paralelamente, el hecho que su teatro sea anterior a "María”, el que pertenezca a ese corto periodo de su vida, en el que escribe toda su obra más representativa, ha permitido indagar en nuevos descubrimientos acerca de su biografía, y el valor que tenía el teatro en su vida. La cuestión es señalar cómo este teatro no puede seguir siendo tratado por los estudios isaaccianos como si nunca hubiera existido.

Palabras Clave: Jorge Isaacs, teatro desconocido, dramaturgia romántica, revaloración y contextualización histórica, revelaciones biográficas, enigma de María.

Abstract: This article is the result of an investigation about the unknown theatre of Jorge Isaacs. The traditional criticism assessed negatively the dramaturgy of his three plays, registered in the romantic aesthetic of the mids of 19 th Century. Replacing this theatre in the cultural and political context of its time, is revealed the historical meaning of a theatre whose romatic charge has been unkown and denied, under the acussation of being an Frenched and Foreigner theatre. In the other hand, the fact that this theatre being former to 'Maria', the fact that belongs to that small period of the life of Isaacs, in wich he wrote all his most representative works, has allowed to inquire in news discoverings about his biography, and the value of the theatre in his life.

Keywords: Jorge Isaacs, unknown Theatre, romatic dramaturgy, revalue and historical context, biographics revelations, Maria's enigma. 


\section{Introducción. La investigación teatral}

Esta investigación se ha realizado sobre el teatro desconocido de Jorge Isaacs $^{1}$, la época de su juventud en la que su obra dramática fue escrita y el trauma amoroso de su adolescencia, que está en la raíz de su vocación de escritor. Teatro desafortunado, como casi todo el teatro romántico de América Latina, pero, significativo, abrevado en el mismo período y bajo el impacto de la misma frustración que alienta sin descanso la melancolía poética de su novela "María". Más allá de contener una clave puramente subjetiva, es necesario considerar, también, el espíritu colectivo de la revolución política de mediados del siglo XIX que alienta estos dramas. En contraste con su novela insigne, el teatro de Isaacs no es un retrato idealizado de la sociedad de su tiempo, refleja por el contrario, la encarnizada lucha por el poder entre los grupos de élite y las clases sociales, bajo el manto secreto de alegorías extranjerizantes. Se aparta del registro costumbrista que legitima la literatura nacional en ese momento y hace aparecer la maldad de pasiones turbulentas, en un medio arraigado todavía a las instituciones coloniales, que no ha logrado la transformación prometida por la Independencia. Sus límites formales son los del escaso desarrollo de la práctica teatral que condenó el género a no ser más que literatura, para el cenáculo cerrado de unos cuantos abogados y políticos, cultos, pero, en su mayoría reaccionarios. Nunca en vida Isaacs pudo ver su obra dramática, ni editada, ni representada como espectáculo.

Por otro lado, el teatro de Isaacs es importante porque ayuda a comprender su proceso creativo y el que ha seguido su generación: señala los modelos literarios que lo han inspirado y la relectura que hace del canon de su época. La relación con su novela "María" no solo es inevitable sino necesaria, su teatro la antecede, al tiempo que al compararlas se hace evidente el gran salto cualitativo que se ha producido. En solo cuatro o cinco años concibe y da a conocer su obra esencial, escribe poesía, tres obras de teatro y el ciclo se cierra con su gran novela romántica. Este conjunto posee caracteres comunes: tanto su poesía, como su teatro y su novela, brotan de la misma fuente emocional y argumental, es un período corto, intenso, desolado, traumático, que va de 1860 a 1865 . Después, todo ha terminado, ya no habrá nada relevante que haga parte de la historia de la literatura con mayúscula, uno que otro poema, la recopilación de unas décimas, informes políticos, debates de prensa, memorias de pleitos judiciales, al final de su vida, pasados más de treinta años, publica un estudio sobre las tribus indígenas en el Estado del Magdalena y el anuncio de una trilogía de novelas históricas, nunca desarrolladas. 
Hay que tener en cuenta, también, que la investigación teatral en Colombia tropieza con muchos vacíos, está muy poco desarrollada, salvo las contadas excepciones de los maestros Carlos José Reyes ${ }^{2}$, Marina Lamus ${ }^{3}$, Fernando Cajiao ${ }^{4}$, los más veteranos y sistemáticos, que han bosquejado un panorama de líneas gruesas y generales, desde puntos de vista distintos, autónomos, donde todavía no se ha dado un diálogo sobre las características definitorias de cada época. A partir del período de la Independencia no existe un canon asequible, en ediciones críticas, de los autores y las obras esenciales de la historia del teatro nacional. En comparación con otro género literario, casi toda persona medianamente culta podría citar algunos de los poetas colombianos indiscutibles, así como el canon básico de nuestras novelas esenciales, me refiero a que lo podemos hacer con una cierta seguridad de la experiencia estética habida con sus obras, pero, con el teatro colombiano no sucede lo mismo. La mayor parte de ese teatro nunca se volvió a ver, si es que alguna vez se vio, ni a leer, no está en la actualidad de la conciencia pública, no existe en la vida cultural, si es que alguna vez existió. No es, pues, solo el caso de Isaacs, como si fuera un caso atípico, exótico. La vida del teatro en nuestro país ha sido efímera y no ha dejado una huella perdurable, una tradición a seguir. Esta precariedad en el vallecaucano resulta aleccionadora por el renombre indiscutible del autor, su teatro no trascendió, no tanto por indiferencia sino por política, nunca se supo si era bueno o malo, todo lo cual es un retrato desesperanzador de los graves problemas del desarrollo frustrado del teatro colombiano.

\section{La aparición de las obras}

10 Entre los manuscritos del archivo de Jorge Isaacs, depositados en la Biblioteca Nacional, la investigadora y escritora María Teresa Cristina encontró cuatro cuadernos con tres obras completas del teatro ignorado del autor vallecaucano: Amy Robsart, María Adrián

y Paulina Lamberti. Las tres fueron publicadas en edición crítica en 2007, a cargo de la profesora Cristina, en el marco del gran proyecto de edición de la obra completa de Isaacs $^{5}$. La última de ellas, Paulina Lamberti, había sido publicada por Rafael Maya, en su revista Bolívar, en 1952, con muchas reservas ideológicas y valorada negativamente ${ }^{6}$. No hay noticias de que haya trascendido, en el sentido de que haya suscitado estudios o comentarios y mucho menos que haya interesado a alguien para llevarla a la escena. Pasados 140 años de haber sido escrita, en noviembre de 2005, el Grupo de Investigación Teatral Univalle, bajo la dirección del Maestro Alejandro González, hizo el estreno insólito de Paulina Lamberti, en el Teatro Municipal de Cali. El hecho fue sobre todo un homenaje y un rescate arqueológico de la dramaturgia olvidada de Isaacs. El descubrimiento de este teatro revelaba un ángulo nuevo del autor de "María". Estas obras dramáticas, configuradas plenamente como estructuras acabadas, no eran ejercicios sueltos o deshilvanados de un colegial o borradores ingenuos del escritor en ciernes, claramente habían sido concebidas y realizadas como tres obras perfectamente 
bien hechas y con el dominio técnico necesario del género dramático. Isaacs tuvo una idea clara del oficio del dramaturgo, había sido persuadido eficazmente, como muchos de su generación, acerca del teatro como instrumento de educación pública. Era un joven romántico, dotado de una sensibilidad especial, el teatro apareció en su vida como un lugar mágico, allí se daba forma tangible a los sueños, a las ilusiones, era un espacio de libertad, al margen de la vida cotidiana y provinciana, alejado de las convenciones sociales, allí se podían expresar y estudiar las pasiones que bullían en su interior.

No sabemos nada del proceso de escritura teatral de estas obras: ¿Las escribió una por una o simultáneamente? ¿Cuál es el orden cronológico de su escritura? ¿Anteceden a "María", como parece, o surgen todas estas historias de la misma caldera literaria de los años 60-65? Una cosa es evidente: los tres manuscritos de estas obras son textos acabados, completos, no tienen correcciones sustanciales, salvo, como señala María Teresa Cristina, cambios de títulos, anotaciones, tachaduras. La que presenta una cierta reelaboración es "María Adrián”, cuyo título definitivo quiso que fuera "Los Montañeses de Lyon”. Las otras dos no presentan variaciones. Lo que se puede indicar es que no son borradores o fragmentos, ni tampoco unos cuadernos dejados por allí al azar, son estructuras textuales terminadas y conscientemente elaboradas. Es claro que Isaacs tuvo en gran estima su obra teatral, intentó publicarla junto con "María", pero, no pudo realizar dicho proyecto; lo concreto es que conservó con celo sus manuscritos y los legó a la posteridad, como parte integral de su literatura y su vida. Lo que aquí se ha intentado es responder esta cuestión: ¿Cuál es el lugar de este teatro en la época y en la vida de Isaacs?

\section{Vocación dramática}

En las biografías de Isaacs ${ }^{7}$ se registra tan solo como un dato, entre otros, su paso a los once años, por el colegio del Espíritu Santo en Bogotá. Creemos que estos son los años decisivos de su formación romántica, allí nace su interés por la literatura y su vocación dramática. Esos años van de 1848 a 1853, corresponden a sus estudios secundarios y a la separación del "paraíso" de su infancia, en el Valle del Cauca. Ese colegio fue por entonces una institución innovadora en la construcción de la República colombiana: su educación era laica, en un medio dominado por los colegios confesionales; en vez del griego y el latín, los referentes lingüísticos de la tradición colonial, se enseñaban el inglés y el francés, las lenguas modernas; y una particularidad curricular marcaría a muchos de sus jóvenes estudiantes: se leía y representaba el teatro de esas nacionalidades, algunas veces en esas lenguas y muchas otras en traducciones al español. Allí se está produciendo un verdadero movimiento de ruptura con la herencia cultural y el modelo de vida de la colonia española, cuya vigencia seguirá siendo muy poderosa.

Como se puede constatar, en el primer párrafo de "María”, su autor indica su paso por dicho colegio y reconoce la importancia de su fundador: Don Lorenzo María Lleras. La cuestión es que esos nombres, el del colegio y su fundador, fueron censurados en varias de las ediciones de la novela, solo aparecieron en la edición de 1891, casi treinta años después de publicada. El caso es que Don Lorenzo María Lleras era un liberal santanderista, inscrito por la historia en la segunda generación republicana, educada bajo la influencia intelectual de Francia, Inglaterra y los Estados Unidos. Su proyecto no era otro que el de cambiar la vieja tabla de valores coloniales, hispánicos, por un modelo liberal de inspiración anglosajona. 
La descripción detallada de Andrés Soriano Lleras ${ }^{8}$, en su biografía de Don Lorenzo María Lleras, muestra que las actividades del colegio del Espíritu Santo resultan, todavía hoy, insólitas y pedagógicamente revolucionarias: allí los estudiantes y los profesores traducían el teatro romántico de su época, luego esas obras eran llevadas al escenario teatral del colegio, dotado de tramoya, escenografía y vestuario, en sesiones abiertas al público bogotano, en un teatro para 650 espectadores, cuyos estrenos han quedado registrados en el periódico cultural del colegio, denominado significativamente "Repertorio Teatral del Colegio del Espíritu Santo". De la mano de este gran educador y por muchos considerado el padre del teatro colombiano, nació toda una generación de jóvenes dramaturgos nacionales, la primera, entre quienes se pueden citar a Santiago Pérez, José María Samper, Honorato Barriga, Lázaro María Pérez y Constantino Franco, entre otros.

A este colegio llegó Isaacs en 1848, allí se encontró con su hermano Lisímaco y estudió durante cuatro o cinco años consecutivos. Ellos eran para esa época los hijos de un gran terrateniente del Cauca, de origen inglés, judío converso, había sido alcalde de Cali, hombre prominente, había venido de Jamaica, poseía visión y conexiones internacionales, es lógico pensar que sus hijos estudiaran en un colegio laico, orientado hacia las lenguas modernas, cuya filosofía esencial se basaba en la tolerancia religiosa, la apertura del país hacia la inmigración europea, el desarrollo industrial y la protección de los derechos individuales. El otro aspecto crucial del colegio era la importancia que tenía el teatro en su organización curricular, algo que resulta insólito, salvo que entendamos que la actividad teatral era en parte un instrumento para el aprendizaje del francés y el inglés. No era, pues, el teatro una diversión extracurricular, era una práctica formativa al interior del estudio de las lenguas modernas, desde luego, operaba como entretenimiento para una amplia comunidad educativa y estimuló el conocimiento de la literatura romántica. El genio literario y dramático de Isaacs tiene aquí sus raíces.

\section{La Revolución Radical}

Entre 1848 y 1854, exactamente el período de formación secundaria de Jorge Isaacs en Bogotá, la denominada generación Radical o Gólgota del partido liberal colombiano ${ }^{9}$, provoca una extraordinaria conmoción política conocida como la Revolución Neogranadina. Es la etapa en la que se inicia el verdadero desmonte del Estado Colonial, nacen los dos partidos tradicionales del país; con el gobierno del presidente José Hilario López en 1849, se da inicio a la denominada hegemonía liberal, se crean los Estados Federales, se expide en 1851 la Ley de abolición de la esclavitud, se reduce el poder eclesiástico al separar claramente las relaciones entre la iglesia y el Estado laico, entre otras cosas esta pierde el monopolio de impartir el saber, se dividen y ponen en venta los Resguardos Indígenas, en fin, una serie de cambios radicales que se producen a mediados del Siglo XIX y cuyo balance histórico sigue siendo muy polémico. Para algunos historiadores, como Indalecio Liévano Aguirre ${ }^{10}$, esta generación radical estaba compuesta por peligrosos soñadores de utopías, ignorantes de la realidad nacional; para otros, como Germán Colmenares ${ }^{11}$, se les debe reconocer su intento de quebrantar las chocantes desigualdades sociales y raciales que persistían inamovibles en la nueva república. Este es el clima político en la década de 1850 que habrá de vivir Isaacs, un clima de cambios y grandes confrontaciones que directa o indirectamente se reflejará en su teatro. No obstante, lo más importante para este estudio, es la conexión del autor caucano con el teatro romántico francés, que llega de la mano con la generación Radical. 
Este último es el tema decisivo en la formación de Isaacs como escritor: la influencia que tuvieron en la inteligencia neogranadina los escritores franceses, particularmente, ese olimpo literario que giró en torno a Lamartine, Victor Hugo y Alejandro Dumas, entre los más importantes. No sobra recordar lo que dice Donald MacGrady en su biografía de Isaacs: en su análisis de "María" refiere como no cabe duda que el caucano imitó conscientemente las novelas francesas de Saint-Pierre y Chateaubriand. En su libro "La personalidad histórica de Colombia" ${ }^{2}$, el historiador Jaime Jaramillo Uribe señala que para comprender el período que va de 1850 a 1870 es necesario entender que a mediados del Siglo XIX se produce un afrancesamiento de la cultura colombiana, fenómeno que durará treinta años. Es claro que la conciencia intelectual y moral de Isaacs, como la de toda la generación Radical, será moldeada por los escritores románticos franceses, ellos constituyen su horizonte estético.

\section{Costumbrismo Vs Romanticismo}

Si en el plano político hay, entonces, una áspera batalla entre los recién fundados partidos Liberal y Conservador, en el plano literario habrá una lucha no menos apasionada entre románticos y costumbristas. A la postre, la genialidad de Isaacs consistió, entre otras cosas, en mezclar estas dos tendencias en su novela "María". La cuestión con su teatro es que se mantuvo, invariable, ligado a su romanticismo radical. El panorama cultural que se le presentó a Isaacs fue más o menos el siguiente: pasada la Independencia y consolidada la vida republicana en Colombia, surge en la literatura nacional la llamada Generación Costumbrista ${ }^{13}$, cuyo propósito era, según lo ha planteado la escritora e investigadora Elisa Mujica, hacer el inventario del patrimonio nacional, reconocer lo propio, sobre todo, iniciar el proceso de la construcción de una identidad nacional. Se trataba de descubrir o recrear la singularidad de una nación que se había liberado de la colonia española. Ahora bien, los modelos de este costumbrismo, los primeros maestros en la elaboración de los "Cuadros de Costumbres" fueron, precisamente, los escritores españoles como Espronceda y Mesonero Romanos, paradoja que revela los caminos contradictorios de la cultura: ¿cómo nuestra propia idiosincrasia, nuestra propia autenticidad hundía sus raíces, más allá de la ruptura política, de la guerra, en la lengua española y en la cultura ibérica? Debían pasar, todavía incluso hoy, muchas generaciones, hasta tanto las tres etnias se olvidaran o mestizaran o reciclaran o afirmaran sus orígenes, en las dinámicas de la nueva nacionalidad multicultural. 
Los escritores románticos colombianos, radicales, afrancesados, de mediados del Siglo XIX, se enfrentaron a un contexto de claro predominio del pensamiento costumbrista. En este sentido, es de notar, cómo el descubridor y promotor de Isaacs, Don José María Vergara y Vergara, él mismo es un connotado costumbrista, además, fundador de la famosa Tertulia "El Mosaico" de Bogotá. No por casualidad, la primera novela colombiana de cierta importancia, "Manuela" de Eugenio Díaz, publicada en 1858, fue rápidamente identificada como la novela nacional ${ }^{14}$. En esta novela se retratan con toda claridad las amenazas contra la hacienda tradicional provocadas por las radicales reformas liberales de mediados del siglo. En una perspectiva más literaria que sociológica, "Manuela", en la elementalidad de su propósito, puede ser leída como una respuesta a los excesos retóricos e idealistas de los románticos franceses. La literatura costumbrista, defensora de lo popular, se convertirá en un bastión del conformismo y en este contexto el teatro romántico va a tener muy pocas opciones.

Hay, pues, una lucha estética e ideológica evidente, entre dos posiciones políticas contrapuestas, frente al proyecto cultural de la nacionalidad colombiana: de un lado, los costumbristas conservadores, que defienden la tradición hispánica, reconocida como la verdadera esencia de lo nacional, defensa que adquiere tonos dramáticos, al leer estas palabras del ecuánime José María Vergara y Vergara: "Negar nuestro origen racial y querer ser engendrados por otras razas, es algo monstruoso y perverso" ${ }^{15}$. Del otro lado, los románticos liberales no se quedaban atrás, criticaban ferozmente la herencia colonial española, atribuían el atraso del país a la intolerancia, el despotismo, el fanatismo y a la codicia española. Para el liberalismo radical la nación colombiana tenía dos taras que había que combatir: la barbarie aborigen y la barbarie de la colonización española. La nueva nación colombiana, pensaban y proclamaban, había de ser construida sobre la influencia de otras naciones: Francia, Inglaterra y los Estados Unidos. De estas influencias se crearían instituciones educativas y culturales como el colegio de Don Lorenzo María Lleras, al que nos hemos referido.

\section{Recepción negativa}

En este horizonte de apasionada confrontación, donde se debaten los rumbos de la construcción urgente de una nueva identidad nacional, Isaacs habrá de responder con su teatro y con su novela "María", dos soluciones distintas y antagónicas. Primero están sus tres obras de teatro y luego "María". La importante biografía de McGrady no menciona el teatro de Isaacs, en cambio da el año de 1864 como la fecha en la que el caucano inicia la escritura de "María", novela que se publica en 1867. En cambio, María Teresa Cristina, a quien debemos el rescate del teatro de Isaacs, señala en su introducción, que estos fueron redactados entre 1859 y 1860, concluye, entonces, que entre la escritura de su teatro y "María" hay una distancia “abismal” de cinco años. ¿Qué tanta distancia hay entre la escritura del teatro de Isaacs y su novela "María”? ¿Qué es lo que provoca el cambio? En una nota del manuscrito, fechada en 1867 , muy conocida, Isaacs menciona que Don Ricardo Carrasquilla tiene el encargo de corregir estas obras, que él viene escribiendo, dice, desde 1860. Después hay otro dato, interesante para lo que queremos plantear, en el que Isaacs dice que comenzó a escribir este teatro, cuando tuvo que hacerse cargo de los pleitos de las haciendas de su padre, el año de su muerte, en $1861 \mathrm{y}$ hasta 1863. La conjetura que tenemos es esta: cuando Isaacs se presenta para leer su poesía en la Tertulia de "El Mosaico" en 1864, allí lleva su teatro y su poesía, ésta es aceptada, pero, su teatro es discretamente rechazado. Inicia, entonces, la escritura de "María" o la reescritura de uno de los dramas teatrales del fin de su adolescencia. Este año de 1864 es un punto de quiebre fatal en la vida del escritor: son rematados todos los bienes de su familia, pierde todos los pleitos y queda desacreditado. Creemos que entre la trama de su teatro y su novela, en el drama de estas cuatro heroínas adolescentes, hay una continuidad secreta que viene de una frustración profunda, la cual palpita en su teatro y se libera en "María". Su teatro y su novela, también su poesía, pertenecen al mismo período de su única y fundamental actividad como creador, están estrechamente relacionados, son el fantasma de un mismo trasfondo afectivo. 
La cuestión es que la crítica contra el teatro de Isaacs se basó en el "abismo" literario entre éste y su magistral novela, al teatro del caucano no se le ha atribuido ningún valor y ni siquiera ha servido como documento de su vida. La crítica negativa se ha mantenido en un plano estrictamente ideológico: ha decretado la "inferioridad" de su teatro frente a "María", al considerar que mientras esta hunde sus raíces en el suelo nacional, sus dramas son de imitación francesa. El olvido y el ocultamiento al que fue sometido su teatro, ha sido heredado del pensamiento de los más importantes críticos colombianos que como Rafael Maya ${ }^{16}$, subvaloraron todo el teatro romántico de mediados del Siglo XIX, al considerarlo exótico, extranjerizante y afrancesado. Su visión era que la literatura que no se ajustase al descubrimiento o a la construcción de la identidad colombiana, entendida en su esencia como lo que está fundado en la lengua española y en la religión católica, no era una literatura a considerar como parte del patrimonio cultural nacional. A eruditos de la importancia de Don Miguel Antonio Caro les parecía que los verdaderos inspiradores del genio nacional debían ser los clásicos del teatro español del Siglo de Oro, el Romancero y Don Quijote, allí estaba todo lo que literariamente valía la pena. En los partidismos apasionados de esta polémica, se ha dejado de ver que la tensión natural entre tradición e innovación, entre lo propio y lo externo, esta ceguera ha sido una constante desde la Revolución de Independencia.

Hay otro elemento importante: en el marco de los estudios literarios y culturales de hoy, se han cuestionado los presupuestos de la crítica literaria tradicional, centrada en un concepto muy cerrado de la calidad estética, estructurada según ciertos patrones rígidamente establecidos, incluso la "mala" literatura, los comics, los folletines, las noveluchas trilladas del tipo Corín Tellado, las caricaturas, en fin, una larga lista de literatura popular o comercial, es hoy un campo de revelaciones psicológicas o sociológicas inesperadas ${ }^{17}$. Con mucha más razón, ahora resulta de interés revisar la literatura teatral del romanticismo o del naturalismo latinoamericano, en una perspectiva que no busca de manera exclusiva enriquecer el canon de lo literariamente consagrado o lo literariamente correcto, sobre todo, en el caso de Isaacs, lo que buscamos es poder leer su obra teatral sin los prejuicios ideológicos que la marcaron durante cerca de ciento cincuenta años. En el teatro "afrancesado" de Isaacs, depurado de toda tentación costumbrista, anclado en un modelo de rebeldía romántica, podemos, tal vez, rastrear la conciencia crispada de una nación desgarrada por violentas tensiones socio-políticas.

\section{LASTRES OBRAS}

\section{Amy Robsart}

Las tres obras son dramas sentimentales, pero, revelan un trasfondo sociológico. No debemos olvidar que la imagen arquetípica del romántico colombiano, está ligada a la imagen de los jóvenes radicales, inmersos en las luchas partidistas de mediados del Siglo XIX. Hay, pues, una relación simbiótica entre romanticismo y radicalismo, cuyos militantes, al decir de Rafael Núñez, minaban el orden social y no tenían otro fundamento filosófico que el anarquismo. 
“Amy Robsart" es una adaptación de la novela épica de Walter Scott titulada “Kenilwoth" (1831). Amy es una joven ingenua, dócil, enamorada, una víctima complaciente, quien se entrega y se casa a escondidas con el Conde de Leicester, hombre perverso e inescrupuloso, que pretende al mismo tiempo la mano de la Reina Isabel de Inglaterra. Este hombre, que encarna al villano del melodrama, tiene un doble juego de erotismo calculado y siniestro, abandona oportunamente a Amy, la encierra en una torre, donde ordena su asesinato. Pese a todas las humillaciones sufridas, hasta el último instante, el amor inquebrantable de Amy permanece fiel a Leicester, quien al final será desenmascarado y procesado por traición a la Reina.

Es considerada la más truculenta de las tres obras, con escenas que rayan en el terror y la tenebrosidad. Ahora bien, lo que interesaba a los jóvenes románticos no era tanto el terror, como el temperamento apasionado de la heroína. La pasión de Amy la convierte en una mártir, esto es lo que les parece admirable: su devoción, su dedicación, su propensión al sacrificio y en esta hoguera incontrolable de sentimientos, el desafío de las convenciones sociales. Esta heroína se sale del molde femenino habitual de la colonia, de la tradición católica, de la institucionalidad, del costumbrismo, su "alma" es temeraria: rechaza el compromiso matrimonial validado por su padre y se casa en una boda secreta con testigos falsos. Esta "heroína" muere a causa de sus propios errores o su bajeza moral, pero, no se arrepiente, buscó la felicidad conyugal en el hombre equivocado, pero, la poderosa, la auténtica, aunque oscura, fuerza de su amor, la redime. El texto de Isaacs está del lado de Amy, tal vez sea una invitación, no explícita, a que la gente luche por lo que siente y cree, así se caiga el mundo. Esta literatura es sintomática de un gran quiebre en la conciencia cultural de la generación de Isaacs, emerge la defensa del "Yo individual" como clave de la libertad verdadera, santo y seña filosófico de los radicales.

\section{Los Montañeses en Lyon}

La segunda de las obras teatrales de Isaacs, es un relato tomado del libro "La historia de los Girondinos" de Lamartine ${ }^{18}$, el caucano la titula "Los Montañeses en Lyon". Trata de la época más sangrienta de la Revolución Francesa, la ciudad de Lyon enarbola la bandera de la monarquía, los Jacobinos o Montañeses le ponen sitio a la ciudad para sofocar la rebelión, es un hecho histórico, la ciudad quedará en ruinas, la nobleza diezmada, la flor de la aristocracia será fusilada o guillotinada sumariamente. El foco de interés dramático tiene como telón de fondo un tribunal revolucionario donde, entre mucha gente, se juzga a una aguerrida joven plebeya de nombre María Adrián. Ha combatido en las calles contra el ejército jacobino, será juzgada y condenada, sus motivos no dejan de ser admirables y desconcertantes: ama a un joven noble en cuya familia ha sido criada y educada, un amor que viene desde la infancia, tal y como los prefiere Isaacs, un motivo que como veremos tiene un arraigo profundo en su psicología. Como en "María”, la novela insigne, el joven Luciano, primogénito de los Condes de Gramont, regresa a su casa desde París, después de una ausencia de largos tres años, ya es un hombre, vuelve para defender la ciudad y se reencuentra con la bella y adorable María Adrián de diecisiete años. 
Isaacs presenta tres conflictos simultáneos: Luciano y María son descritos como "hermanos" de crianza, la madre hace pesar sobre ellos el fantasma de una prohibición moral; el hecho de pertenecer a estratos sociales distintos pone en evidencia la imposibilidad o la inconveniencia de un matrimonio entre un aristócrata y una plebeya; y finalmente el hecho político de la guerra civil entre aristócratas y jacobinos, entre los partidarios de la monarquía y la república. En esta dirección, María a su vez tiene un conflicto al interior de su familia, con la que no ha vivido, su hermano Jaime ha tomado partido por los Jacobinos y la quiere casar con Raimundo, uno de ellos, a quien le debe su carrera y su posición social en la nueva república. La fatalidad se cierra sobre los amantes, María es colocada en la disyuntiva de salvar a Luciano y casarse con Raimundo o engañar a Raimundo con una falsa promesa de matrimonio y huir con Luciano, corriendo el peligro de ser descubierta. El conflicto político marcará el desarrollo del argumento y llevará los amantes a la muerte. La tensión trágica se concentra en la atormentada conciencia de María: en el paroxismo sentimental del último acto, asediada por la pasión baja de Raimundo, ella lo mata y es conducida al cadalso, mientras del otro lado de la cárcel, donde había estado confinada, Luciano es fusilado a las afueras de la ciudad, con un grupo de los aristócratas de Lyon.

Haciendo una paráfrasis y una digresión de lo dicho por Jesús Martin Barbero en su texto sobre el melodrama $^{19}$, el teatro de Isaacs es claramente un teatro "de género", sigue una matriz literaria que nace justamente con la Revolución Francesa, período de la transformación de "la canalla" en pueblo. Ahora bien, es necesario ver estos melodramas como espejos de la conciencia colectiva: época de inmensas desgracias sufridas por inocentes víctimas. En la polarización esquemática de los personajes, si María es la encarnación de la inocencia y la virtud, Raimundo es la personificación del mal, lleno de disimulos y disfraces, es el Robespierre de Lyon, dueño de la vida y la muerte de los prisioneros. En la obra de Isaacs el trasfondo es político, pero, en el primer plano hay una reflexión moral: María no es que se enfrente a hombres que profesan otra ideología política que ella no comparte. No, ellos son simplemente hombres astutos, ambiciosos, oportunistas, hombres ruines, sin escrúpulos de conciencia, que buscan beneficios en medio del caos de la vieja sociedad. 
Uno puede pensar que Isaacs no solo es consciente de las transformaciones de su propio medio, sino que expresa en su obra los cambios que sufre su propio entorno familiar. Cuando escribe estas obras, tras la muerte de su padre, el autor caucano se enfrenta a los acreedores, poco a poco quedará acorralado en medio del papeleo judicial, pagarés, embargos, remates, la escritura teatral es claramente su evasión, su liberación. No es que esa realidad inmediata pase al cuerpo material de la obra, sino que esa realidad, cuyo impacto psicológico es reconocido, impregna la visión y el sentimiento de los personajes. Él vive este periodo como uno de los años más crueles de su vida, hace muchos enemigos, pierde todas las batallas en defensa de la herencia de su familia, hasta que finalmente deberá enfrentar la ruina y la pobreza. Entre la época en que su padre se convirtió en un próspero terrateniente, en la década de 1830, y la de la Revolución Radical del medio siglo en Colombia, los cambios han sido dramáticos, no solo por el tema del fin de la esclavitud, en el año de 1851, que afectará la economía de las haciendas de todo el Estado del Cauca, también por la introducción del capitalismo comercial que promueve el libre cambio y rompe la estructura socioeconómica colonial aún vigente. La obra se puede leer como una alegoría en cuyo fondo están las transformaciones revolucionarias de los Radicales colombianos, como una denuncia del fanatismo ideológico, deshumanizado, contra las élites del viejo orden hispánico, es decir, los folletines del teatro romántico francés son el molde a través del cual se retrata una nueva sociedad donde la venganza de clase, la codicia y la corrupción se han entronizado. La experiencia de la pérdida de las haciendas de su padre fue vivida por Isaacs como un despojo, como una trampa enmarañada de argucias jurídicas que lo hundieron en la desesperación.

\section{Paulina Lamberti}

La última obra teatral de Isaacs es "Paulina Lamberti". Ya he indicado antes que la cronología de estas obras no es concluyente. Al parecer la primera es "Amy Robsart” y, por ser la más coherente en su estructura dramática, la última sería "Paulina Lamberti". No es este el orden de la edición de María Teresa Cristina, quien pone al final "Los Montañeses en Lyon". Se vuelve así al problema del orden de la escritura de estas obras, sobre el que no hay certeza. Nos hemos decidido por una consideración de calidad estética, en la misma idea de Rafael Maya, que seleccionó a Paulina como la más lograda, en ese sentido es la última, por su, digamos, evolución como dramaturgo. El único dato cierto es que el 24 de octubre de 1867, Isaacs le entregó, a su amigo de la tertulia de "El Mosaico", Don Ricardo Carrasquilla, desde hacia una década consagrado autor dramático neogranadino, los manuscritos de sus "ensayos dramáticos", como él mismo los calificó, para que los revisara y corrigiera, cosa que nunca sucedió.

La obra se ubica en la historia de Francia, en el período del Imperio Napoleónico: 1804-1814. Su contexto ya no es como en "María Adrián" la guerra civil, sino la resistencia y el resentimiento de la vieja nobleza al nuevo poder que impuso la Revolución. La trama se organiza en torno a un triángulo amoroso que estalla al principio de la obra y desgarra la conciencia de los protagonistas: Paulina, hija única de un general napoleónico, se ha casado con Jacobo de Carignan, hombre apasionado y orgulloso, en contravía de la sociedad que le ha tocado vivir. Su familia perteneciente a la nobleza lo perdió todo con la Revolución, se ha convertido en conspirador y se ha batido en duelo por el amor de su infancia, la hija del Conde de Valmont, Mirta. La matriz del melodrama romántico se hace evidente: Paulina se ha topado con el hombre equivocado, ella que es un depósito de dulzura e inocencia, intentará en vano salvar su matrimonio y la vida de Carignan. 
A diferencia de las dos obras anteriores, en "Paulina Lamberti" Isaacs ha realizado un trabajo de economía textual sorprendente: la estructura argumental está más comprimida, los acontecimientos están concentrados, todo está bien articulado a unos pocos motivos determinantes: la cartera perdida, la conspiración desenmascarada, el amor de Paulina por salvar su hogar, la autodestrucción de Jacobo, la perfidia de Valmont y su pasión turbia por Paulina, la frialdad de Mirta ante las desgracias de su destino y la fatalidad que planea sobre el desenlace inevitable. La fábula es mucho más orgánica, su tensión e interés esta menos en la dinámica de los hechos y mucho más en la psicología de los personajes. La trama avanza en el sentido de una fatalidad trágica provocada por la "hybris" de Carignan. Salvo la escena final, no hay giros espectaculares, ni visiones góticas, ni subterráneos, ni torres tenebrosas, ni puertas invisibles, el relato dramático se atiene acertadamente a la lógica de las relaciones de conflicto y ha tomado distancia de la novela de aventuras.

Son conocidas las cartas de Isaacs donde manifiesta sus dudas de si titular la obra con el nombre de "Paulina Lamberti", como finalmente quedó, o con el nombre de "Jacobo de Carignan". No es una cuestión carente de significado, pues es claro que la acción dramática gira en verdad en torno a Jacobo. La concepción de este personaje es provocadora o abismal, su conducta es del todo ambigua y problemática: la familia Lamberti le ofrece la salvación y el perdón, pero, él se hunde en sus contradicciones, en la fiebre de una pasión trágica, no acepta la solución burguesa de un matrimonio sin amor. Mirta rechaza la locura de su comportamiento y al final Jacobo, en el vértigo del abismo que se abre a sus pies, se suicida, en un acto de transgresión para liberarse de un mundo mediocre que lo encadena. Isaacs ha diseñado con Jacobo de Carignan la antítesis del personaje de Efraín en "María", este contraste lo hace sumamente interesante: reivindica su libertad para luchar contra lo que odia y huir hacia lo que ama. La moralidad social piensa que, en la situación de Jacobo, su reacción debería ser de gratitud, sería lo sensato, lo normal; sin embargo, Jacobo siempre parece estar a punto de cometer alguna otra infamia, pertenece a esa extraña clase de hombres que inconscientemente se adentran en la destrucción y el caos. Cuando le ofrecen una salida hacia la tranquilidad, la prosperidad, el buen nombre, la dignidad social, elige el sufrimiento, la tormenta, arremete contra todo y se hunde en el barro.

\section{Alegoría y trauma}

¿Qué significa este teatro en relación con el teatro de su tiempo? ¿En qué medida su teatro contiene, como se ha probado en su novela "María", el relato inconsciente, vivido e imaginado, de algunos pocos acontecimientos determinantes de su biografía?

Al reinsertar a Jorge Isaacs en las tensiones culturales de su tiempo, es posible probar que su teatro alude y dialoga con la realidad histórica de su medio, como todo el teatro romántico latinoamericano. Adopta la máscara de las fábulas del folletín francés y la matriz del melodrama, utiliza los tópicos de la sensiblería romántica, navega en una corriente estética internacional, al margen de la cultura tradicional hispánica; no obstante, es necesario ver otra cosa, lo denotativo es Francia e Inglaterra, pero, lo connotativo es Colombia. Sobre todo Francia, con sus grandes y violentas transformaciones revolucionarias, hace posible un paralelo alegórico de la lucha de las repúblicas americanas por superar la sociedad colonial. Muchas de las obras teatrales más representativas de la década de 1850, como el

"Jacobo Molai" (1851) de Santiago Pérez, vinculado al movimiento 
teatral promovido por Don Lorenzo María Lleras, en su teatro del Colegio del Espíritu Santo, basaban su fábula en los conflictos políticos europeos: Molai es el hijo clandestino y perdido de la reina de Francia, quien habrá de convertirse, nada menos, que en el Papa Clemente V, pontífice sombrío y cruel. Esa es la anécdota, pero, la obra tiene un fuerte sentido antimonárquico y anticlerical, denuncia la perversa participación de la iglesia en la política, utilizando el arma de la Inquisición. El teatro era claramente el escenario donde se ventilaban las diferencias ideológicas de los partidos políticos, un drama como "El Misionero" de Eladio Vergara (1851), expresa la lucha a muerte que se libraba entre Masones y Jesuitas, en un contexto crispado de intolerancia y violencia. La crítica contra el teatro de Isaacs como decadente y desarraigado de la realidad nacional, oculta o tergiversa su trasfondo alegórico, es decir, el hecho que su anécdota es una figuración engañosa, un relato que oculta otro relato. Un análisis político del teatro de Isaacs, mas detenido, más puntual, revelaría su amplitud de criterio y su talante abierto, reflexivo, tolerante: en "Amy" deja una visión positiva de la Monarquía Inglesa; en "María Adrián" devela la brutalidad de los Jacobinos que arrasan la ciudad de Lyon y en "Paulina Lamberti" cuestiona la frustración y la perversidad de la nobleza en contra de los cambios sociales. No hay en el escritor teatral que es Isaacs un patrón ideológico cerrado y excluyente. Ahora bien, su teatro es menos "político" que el de sus maestros radicales y más subjetivo, indaga más la intimidad moral de la conducta humana, el impacto emocional del amor que no puede ser.

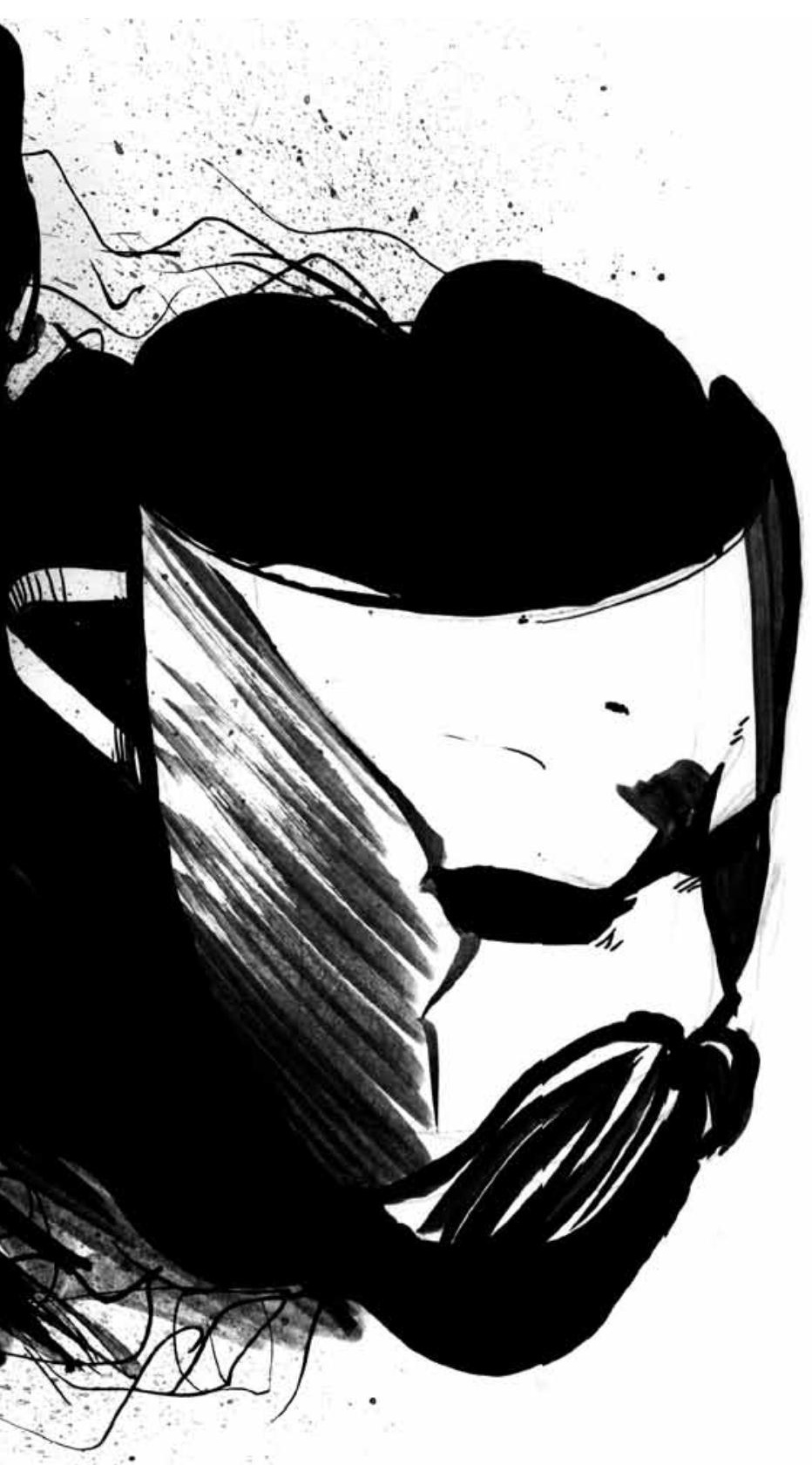

La experiencia del amor en el teatro de Isaacs, como en "María", desemboca en la disolución y en la pérdida. A diferencia del espiritualismo romántico que culmina con una especie de embriaguez cósmica o de misticismo oscuro que sublima el dolor ${ }^{20}$, en el autor caucano solo queda desolación y muerte. ¿Se trata de una "simbolización" de su propia existencia? ¿Su poética teatral en últimas es una descarga de las tensiones de su propia alma o de su afectividad inconsciente? No cabe duda que de forma reiterativa en la biografía de Isaacs se han cuestionado por la realidad de la existencia de la niña "María" de la novela. Las cuatro heroínas de su obra son niñas-adolescentes, tres de ellas se precipitan hacia la muerte. La precocidad del amor romántico es perturbadora: Novalis de 22 años se prometió en matrimonio con la frágil y pequeña Sophie Von Kuhn, de apenas 13 años, muerta prematuramente. El destino de muchos autores románticos es enteramente análogo. Esta muerte estará en el centro de su literatura, es parte esencial de la psicología romántica, el límite entre el "afuera" y el "adentro" del escritor se borra, su obra edifica el mito de su propia vida, reconstruye el camino de su angustia, su fracaso, la hora temible de la separación. 
El estudio del teatro de Isaacs resulta importante en la comparación con su novela "María", incluso con su poesía, no en la perspectiva negativa de la calidad estética, sino en la realidad del amor sufrido, que opera como un trauma en los cortos años de la escritura de estas obras. Su teatro, como su novela, se origina y se realiza en un corto periodo: de 1861, fecha de la muerte de su padre, a 1867, fecha de la publicación de "María". Donald Mcgrady en su biografía de Isaacs da otro dato interesante: todos los poemas autobiográficos de Isaacs tienen la fecha de 1860. Ya en estos poemas habla de "María” y en uno de ellos dice que María estaba casada, a su regreso de Bogotá. Ahora bien, como Macgrady no da crédito a la existencia real de María, saca una conclusión sorprendente, declara que como era de suponer, ese había sido el amor de un niño por una mujer mayor, con toda probabilidad María era una sirvienta de la casa paterna. Eso sí, agrega, esa mujer no pudo ser el modelo de la heroína de la novela. El enigma de la existencia real de María y la frustración del amor, están en el centro de la obra de Isaacs: poesía, teatro y novela. Ha tenido que ser una experiencia real, traumática y no imaginada.

La otra biografía de Isaacs ha comenzado a ser reescrita por un antropólogo de la Universidad Nacional, Luis Francisco López Cano, en su libro "La Tumba de María Isaacs ${ }^{21}$. Al cotejar algunas fechas y datos, el insoluble rompecabezas acerca de la María de la realidad y el conjunto de la obra de Isaacs, donde se refleja, se hace menos enigmático. En el imaginario popular vallecaucano se ha sostenido la creencia que la protagonista de la novela existió, que había sido una niña traída de Jamaica llamada Esther y que es ella el amor mítico de la infancia de Isaacs. Nunca se ha podido probar nada, el misterio se fue haciendo más espeso: López Cano, en su exhaustivo rastreo por los archivos y los cementerios, ha podido detectar nueve mujeres que comparten la posible identidad verdadera de ese primer amor. Hay una entre todas, jamás mencionada, que es la piedra roseta, en esa especie de arqueología de las tumbas de López Cano, que encaja en el rompecabezas, su nombre es María Manuela Conto Ferrer, prima-hermana del escritor por el lado materno. Siempre se había indagado en la genealogía paterna. No hay en su libro ninguna prueba contundente de esta teoría, pero, ciertos hechos la relacionan, hipotéticamente, con el trauma amoroso de Isaacs y su obra. Veamos.

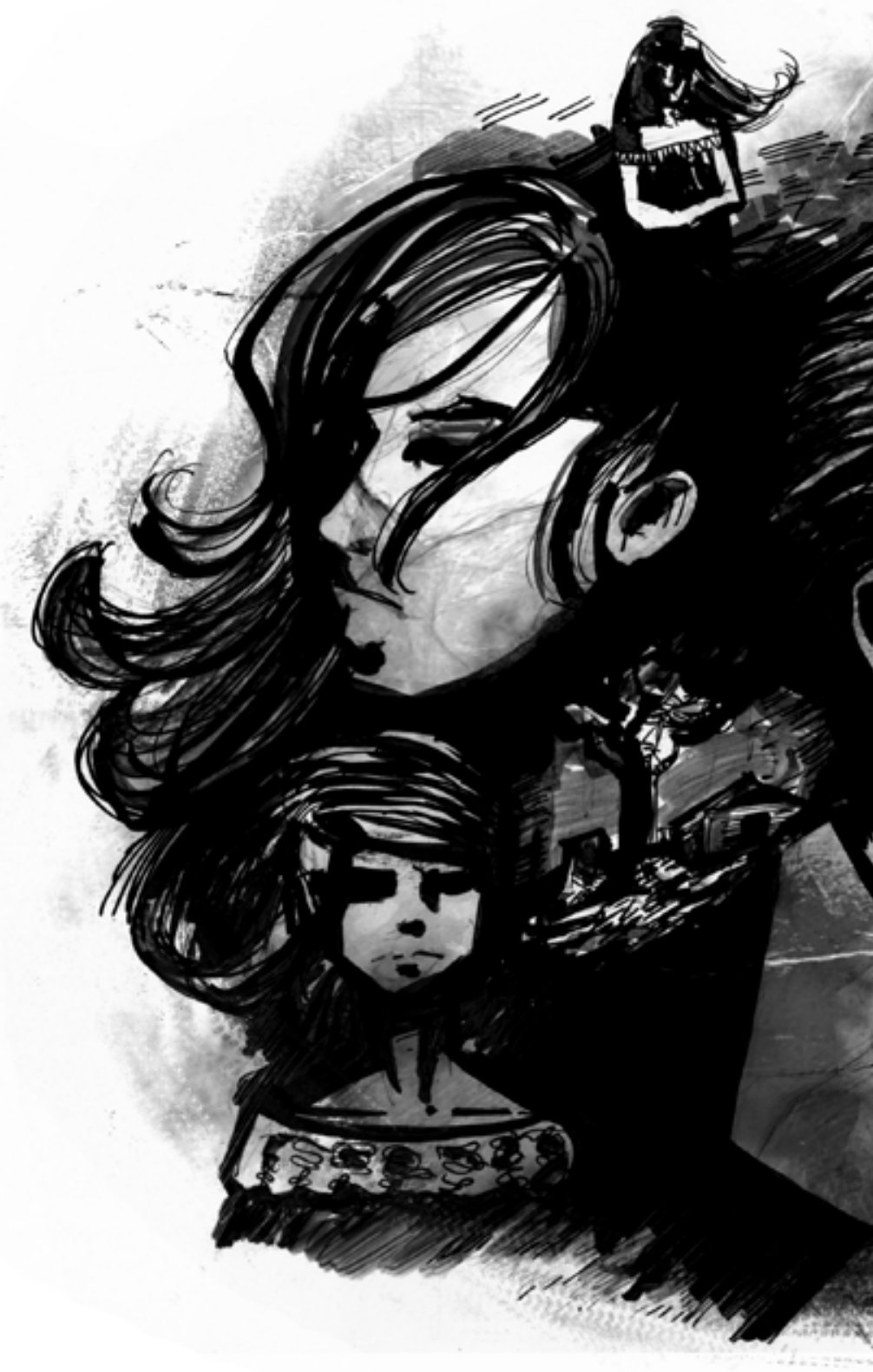


El año crucial de Isaacs como escritor, en el que da el salto creativo fundamental de su obra, es 1864, fecha en que inicia la escritura de su novela "María". Hay cartas suyas sobre la turbulencia de este año, su desolación y su angustia. Ese año contiene un episodio trágico: muere María Manuela Conto Ferrer a los 25 años en El Cerrito. Eso podría no ser nada significativo sino lo relacionamos con 1861, el año de la muerte de su padre y del matrimonio de María Manuela, que como se ve, habrá de durar muy poco. La familia Conto Ferrer vino de Quibdó a Cali, en circunstancias políticas muy dramáticas y estará estrechamente unida a Jorge Isaacs, al punto que éste será Secretario de Educación del Estado del Cauca cuando su primo Cesar Conto, hermano de María Manuela, fue su Presidente. El padre es el gran opositor del amor prohibido de Efraín en la novela y algunos documentos-cartas de amigos refieren con mucha discreción y prudencia cómo el matrimonio de Isaacs en 1856, con Felisa González Umaña, de quien sabemos muy poco, fue un matrimonio convenido por el padre, bajo presiones de circunstancias económicas. Es 1861, el año que se reconoce como el de la iniciación de Isaacs como poeta y dramaturgo, así como el de 1864 inicia el gran salto estético hacia su novela "María". Ambas fechas revelan episodios fundamentales en la vida del caucano y conectan de forma profunda con su vocación de escritor romántico. Si María Manuela es en verdad el nombre celosamente oculto del amor traumático de Isaacs, las fechas de 1861 y 1864 señalan las huellas de la crisis que habrá de expresar en su obra. Lo que hemos querido señalar es que el teatro de Isaacs está subjetivamente conectado con su Novela "María”, las "lecturas congeladas" de la vieja crítica, separaron y condenaron de forma radical su teatro del resto de su obra, bajo condiciones políticas y estéticas que hoy han perdido validez.

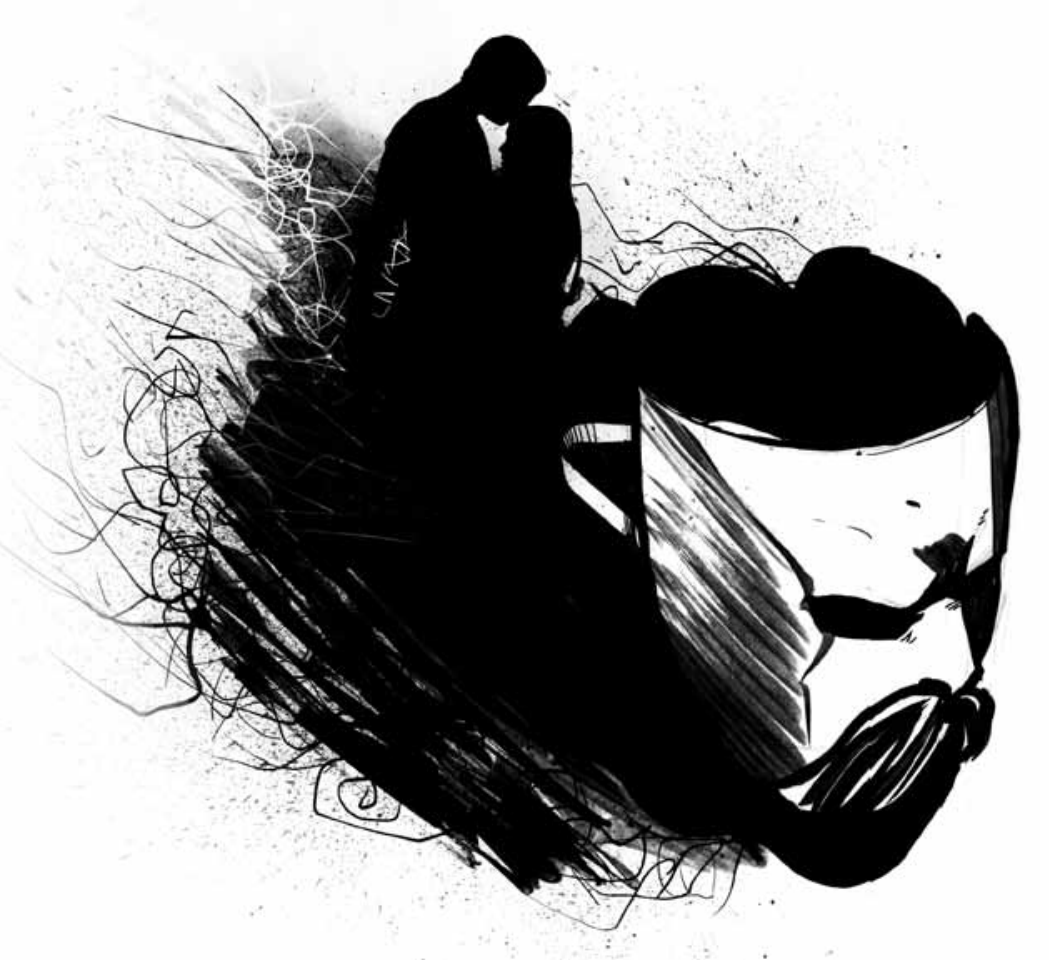




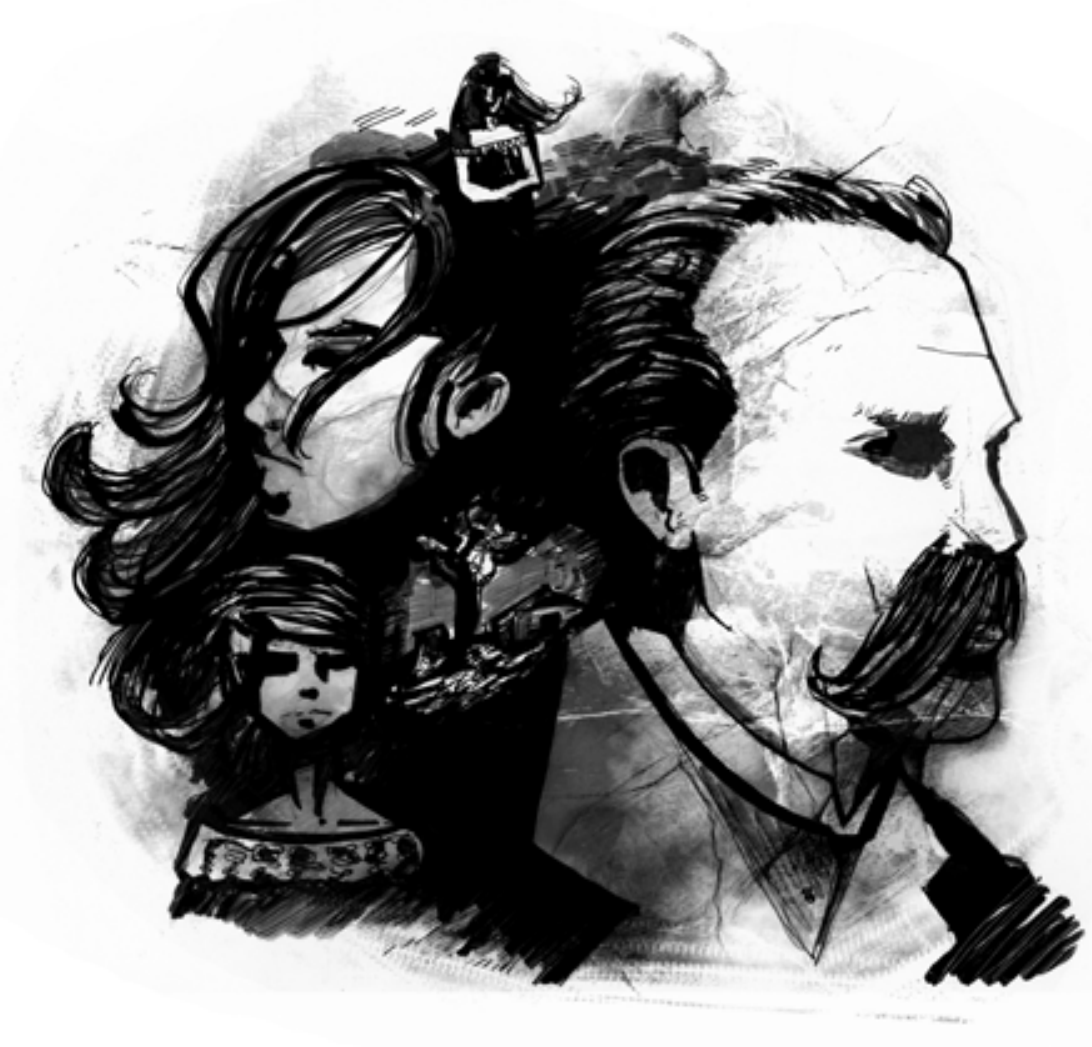

Notas

${ }^{1}$ Doménici, Mauricio. El teatro de Jorge Isaacs: identidades y contextos. Universidad del Valle. Cali. 2012. Esta investigación fue seleccionada y becada en una convocatoria interna de la Vicerrectoría de Investigaciones de la Universidad del Valle en el 2009.

${ }^{2}$ Watson Espener, Maida y Reyes, Carlos José. Materiales para una historia del teatro en Colombia. Instituto colombiano de cultura. Bogotá. 1978.

${ }^{3}$ Reyes, Carlos José. Cien años del teatro en Colombia. Nueva historia de Colombia. Tomo VI. Editorial Planeta. Bogotá. 1989. Este texto y el de la nota anterior contienen perspectivas en proceso del teatro colombiano. El primero "materiales" reunidos de diversos autores sobre distintas épocas. El segundo traza una evolución con una línea interpretativa que va desde la construcción del teatro Colón de Bogotá, hasta el movimiento del "Nuevo Teatro" en los años 70.

${ }^{4}$ Marina Lamus es una experta en el teatro colombiano del Siglo XIX, entre otros muchos estudios. Su aporte más significativo tiene que ver con su extraordinaria investigación de archivo, la que ha permitido ver el teatro nacional desde la materialidad de los grupos y compañías que lo han realizado. Su libro sobre el teatro de América Latina es pionero en el intento de reunir como una totalidad cultural un vasto campo de autores, movimientos y organizaciones teatrales.

${ }^{5} \mathrm{Su}$ visión del teatro colombiano contiene focos de interés distintos a los de Reyes y Lamus: uno de ellos es un capítulo dedicado al teatro indígena, sus fiestas y rituales; en otro dedica un mayor análisis a los autores y algunas de sus obras, algo menos frecuente.

${ }^{6}$ Debemos a la doctora Cristina la edición crítica del teatro de Isaacs, literalmente el rescate de un patrimonio olvidado y perdido de la literatura y el teatro colombiano. Estas obras prácticamente no se conocían y casi nadie sabía que el caucano había sido escritor dramático, los que lo sabían veían esta obra con recelo y desconfianza. 
${ }^{7}$ Uno de los grandes de la crítica literaria nacional, Maya es una autoridad académica indiscutible. Defensor incondicional de la literatura clásica, la que veía en dos corrientes básicas: el mundo clásico antiguo y la tradición española. Del romanticismo solo valoraba la poesía y de esta su máximo representante era Rafael Pombo, junto con Caro y Cuervo. Su visión hoy parece anacrónica, sobre todo por su rechazo radical del Modernismo.

${ }^{8}$ McGrady, Donald. Jorge Isaacs. Universidad Externado de Colombia. Bogotá. 2006 y Velasco Madriñán, Luis Carlos. El caballero de las lágrimas. Litocencoa. Cali. 1987.Estas dos biografías son enteramente distintas: la de Mcgrady es más analítica y crítica, más objetiva, si se quiere; mientras que la de Velasco es una exaltación y una identificación profunda con Isaacs. El primero ignora por completo el teatro de Isaacs y el segundo trata el tema, pero, repite la opinión negativa tradicional en su contra.

${ }^{9}$ Es la biografía esencial sobre Don Lorenzo María Lleras y donde se trata con propiedad sobre su colegio del Espíritu Santo y la actividad teatral que allí se desarrollaba con pasión. Desde luego en su libro "Mi Gente" otro de sus descendientes, el ex presidente Alberto Lleras Camargo, le dedica unas bellas páginas y cuenta valiosas curiosidades sobre la vida del teatro en la familia Lleras. ${ }^{10}$ Una obra dedicada a la época del radicalismo: 1863-1886. Un período que dejó una huella profunda en la historia nacional y, para lo que nos interesa, que promovió la instauración de la educación laica en Colombia.

${ }^{11}$ Se trata de una biografía magistral cuya cualidad más destacada, parece ser la de haber sido escrita sin sectarismos, por un historiador adscrito al liberalismo.

${ }^{12}$ Colmenares, Germán. Partidos políticos y clases sociales. La Carreta Editores. Medellín. 2008. Es la opinión que contrasta la diversa valoración que sobre el Radicalismo hay en Colombia.

${ }^{13}$ En su libro La personalidad histórica de Colombia y otros ensayos deja muy en claro el "afrancesamiento" de la cultura colombiana durante esta época.

${ }^{14}$ Carlos José Reyes hace notar el autor la relación entre el Costumbrismo español y el colombiano, poniendo de presente la secreta continuidad de la cultura hispánica en nuestro medio.

${ }^{15}$ De un lado recoge y resume la polémica en torno al puro valor documental de esta novela de costumbres. Rescata no obstante el indiscutible significado de la obra para la cultura y la realidad colombiana de su tiempo, novela que refleja la resistencia al proceso de reformas liberales de mediados del siglo XIX.

${ }^{16}$ Padilla Chasing, Iván Vicente. El debate de la hispanidad en Colombia. Universidad Nacional. Bogotá. 2008. Es un texto que pone de presente el intenso debate que después de la Independencia se creó, entonces, en torno a la tradición católica española. Aparecen las figuras intelectuales más representativas de este conflicto: José María Vergara y Manuel María Madiedo. El debate de la hispanidad es crucial en el desarrollo político y cultural de la nacionalidad colombiana.

${ }^{17}$ Maya, Rafael. Obra crítica. Tomos I y II. Banco de la República. Bogotá. 1982. Recoge este libro la vasta producción critica de Maya, de particular interés fue para nosotros el capítulo sobre el romanticismo y allí el artículo dedicado a Isaacs.

${ }^{18}$ Culler traza un panorama sobre las teorías literarias vigentes. Tiene un capítulo dedicado a las difusas fronteras de lo que puede ser hoy un texto literario. Los teóricos ven la literatura como una categoría social e ideológica y le atribuyen múltiples funciones que van más allá de sus valores puramente estéticos.

${ }^{19}$ De Lamartine, Alphonse. Historia de los Girondinos. Editorial Continental. México D.F. 1956. En este texto entre histórico y literario, encontramos el relato de María Adrián ante el tribunal, el cual da origen a la obra de Isaac.

${ }^{20}$ De este libro es de vital interés el artículo de Martin Barbero que da cuenta del origen histórico del melodrama y describe los rasgos genéricos que lo caracterizan.

${ }^{21}$ Una obra que combina un cierto tipo de análisis literario y al mismo tiempo mantiene un extraordinario nivel poético en su escritura, pone de presente el carácter místico religioso del romanticismo y le hace una apología al sueño y al inconsciente.

\section{Referencias:}

Doménici, Mauricio (2012). El teatro de Jorge Isaacs: identidades y contextos. Universidad del Valle:Cali.

Watson Espener, Maida y Reyes, Carlos José (1978). Materiales para una historia del teatro en Colombia. Instituto Colombiano de Cultura:Bogotá.

Reyes, Carlos José (1989). Cien años del teatro en Colombia. Nueva historia de Colombia. TomoVI. Editorial Planeta:Bogotá. Lamus Obregón, Marina (1989). Teatro en Colombia: 1831-1886. Editorial Ariel-Planeta:Bogotá. 
(2010). Geografías del teatro en América Latina: un relato histórico. Editorial Luna-Libros:Bogotá.

González Cajiao, Fernando (1988). El proceso del teatro en Colombia. Manual de Literatura Colombiana. Tomo II. Editorial PlanetaColcultura:Bogotá.

Isaacs, Jorge. Obras completas (2007). Compilación de María Teresa Cristina. Universidad Externado de Colombia. Volumen III:Bogotá.

Maya, Rafael (1952). Prólogo a “Paulina Lamberti” en “Revista Bolívar” N 12. Ministerio de Educación Nacional:Bogotá.

McGrady, Donald (2006). Jorge Isaacs. Universidad Externado de Colombia:Bogotá.

Velasco Madriñán, Luis Carlos (1987). El caballero de las lágrimas. Litocencoa:Cali.

Soriano Lleras, Andrés (1958). Lorenzo María Lleras. Biblioteca Eduardo Santos. Volumen XIV. Editorial Sucre:Bogotá.

Sierra Mejía, Rubén (2006). El Radicalismo colombiano del Siglo XIX. Universidad Nacional de Colombia:Bogotá.

Liévano Aguirre, Indalecio (2002). Rafael Núñez. Intermedio Editores:Bogotá.

Colmenares, Germán (2008). Partidos políticos y clases sociales. La Carreta Editores:Medellín.

Jaramillo Uribe, Jaime (1994). La personalidad histórica de Colombia y otros ensayos. El Ancora Editores:Bogotá.

Reyes, Carlos José (1988). El costumbrismo en Colombia. Manual de Literatura Colombiana. Tomo I. Editorial Planeta-Colcultura:Bogotá.

Colmenares, Germán (1988). Manuela, novela de costumbres de Eugenio Díaz. Manual de Literatura Colombiana. Tomo I. Editorial Planeta-Colcultura:Bogotá.

Padilla Chasing, Iván Vicente (2008). El debate de la hispanidad en Colombia. Universidad Nacional. Bogotá.

Maya, Rafael (1982). Obra crítica. Tomos I y II. Banco de la República:Bogotá.

Culler, Jonathan (2000). Breve introducción a la teoría literaria. Editorial crítica:Barcelona.

De Lamartine, Alphonse (1956). Historia de los Girondinos. Editorial Continental: México D.F.

Martin-Barbero, Jesús y Sonia Muñoz (1992). Televisión y melodrama. Tercer Mundo Editores. Bogotá.

Beguin, Albert (1954). El alma romántica y el sueño. Fondo de Cultura Económica:México.

López Cano, Luis Francisco (2002). La tumba de María: génesis y desarrollo de una leyenda vallecaucana. Premio Departamental de Cultura Valle del Cauca. Ministerio de Cultura.

Recibido: marzo 28 / Aprobado: mayo 23 de 2013 